Results: S100B maternal and neonatal blood concentrations were significantly higher at all monitoring time-points in the SSRI $(P<0.001$, for all), whilst proteins' concentrations in healthy mothers and newborns were within normality ranges.

Conclusions: The elevated S100B protein concentrations in maternal and newborn bloodstreams suggest that SSRI exposure, in agreement to adults' findings, can exert CNS sideeffects both in intrauterine and in post-natal periods. Further investigations aimed at investigating short/ long term neurological sequelae in these patients are needed.

148

\section{BRANCHED CHAIN AMINO ACID REQUIREMENTS FOR TERM NEONATES}

F. Maingay-de Groof ${ }^{1}$, L. Huang ${ }^{1}$, G.J. Voortman ${ }^{1}$, C. Chao ${ }^{2}$, Y. Huang' ${ }^{2}$, J.B. van Goudoever ${ }^{1}$

${ }^{1}$ Neonatology, Pediatrics, Erasmus MC Sophia, Rotterdam, The Netherlands, 'Neonatology,

Pediatrics, Fudan Children's Hospital, Shanghai, China

Background: Dietary intake should meet the requirement to obtain an optimal growth and neurodevelopment in the neonate. The essential branched chain amino acids (BCAAs), leucine, isoleucine and valine, are mainly used for incorporation into body protein. Current recommended BCAA requirements for infants 0-6 months (respectively 156, 88 and $87 \mathrm{mg} \cdot \mathrm{kg}^{-1} \cdot \mathrm{d}^{-1}$, ratio $1.8: 1: 1$ ) are based on the amino acid content of human milk. However, human milk fluctuates in composition during lactation and even during a feeding, while milk consumption rate varies widely as well. Questions remain on the validity to use mean amino acid composition of human milk to determine requirements.

Objectives: To quantify the requirement of leucine, isoleucine and valine in term neonates using the Indicator Amino Acid Oxidation method.

Design: Enterally fed term infants received randomly graded intakes of leucine $(15-500 \mathrm{mg} \cdot \mathrm{kg}$ $\left.{ }^{1} \cdot \mathrm{d}^{-1}\right)$, isoleucine $\left(5-216 \mathrm{mg} \cdot \mathrm{kg}^{-1} \cdot \mathrm{d}^{-1}\right)$ and valine $\left(5-236 \mathrm{mg} \cdot \mathrm{kg}^{-1} \cdot \mathrm{d}^{-1}\right)$. Breath samples containing ${ }^{13} \mathrm{CO} 2$ were collected during $\mathrm{L}-\left[1-{ }^{13} \mathrm{C}\right]$ phenylalanine (indicator amino acid) administration, measured by isotope ratio mass spectrometry and analysed using a biphasic regression crossover analysis.
Results: 83 term Asian neonates (birth weight: 3.29 $\pm 0.4 \mathrm{~kg}$, gestational age: $39.4 \pm 1.3 \mathrm{wks}$, postnatal age: $12.6 \pm 5.1 \mathrm{~d})$ were included. The mean requirement (at breakpoint) for leucine, isoleucine and valine was respectively 140, 105 and 110 $\mathrm{mg} \cdot \mathrm{kg}^{-1} \cdot \mathrm{d}^{-1}$ and the upper $95 \%$ confidence interval was 240,152 and $165 \mathrm{mg} \cdot \mathrm{kg}^{-1} \cdot \mathrm{d}^{-1}$.

Conclusion: The requirements of the individual BCAAs are almost twice the current recommendations. A Leu:lle:Val ratio of 1.3:1:1 is more appropriate in term formula.

\section{9}

\section{GESTATIONAL AGE PATTERNS OF FETAL AND NEONATAL MORTALITY RATES: THE EURO- PERISTAT PROJECT}

\section{A. Mohangoo ${ }^{1}$, S. Buitendijk ${ }^{1}$, J. Zeitlin², and the EURO-PERISTAT Network \\ ${ }^{1}$ Prevention and Care, TNO Quality of Life, Leiden, The Netherlands, ${ }^{2}$ Epidemiological Research Unit on Perinatal and Women's Health, INSERM UMR S16, Paris, France}

Background: The recently published European Perinatal Health Report showed wide variability in perinatal mortality rates between European countries. We investigated the gestational age patterns of mortality in order to better understand differences between low versus high mortality countries.

Setting: The Euro-Peristat project developed a list of valid and reliable indicators for monitoring and evaluating perinatal health, including fetal and neonatal mortality. Data from 2004 on 29 countries/ regions were analyzed.

Results: The fetal mortality rate ranged from 2.6 per 1000 births in Slovakia to 9.1 in France (weighted average of 5.4 per 1000 births) and the neonatal mortality rate ranged from 1.6 per 1000 live births in Cyprus to 5.7 in Latvia (weighted average of 3.0 per 1000 live births). In some countries, fetal mortality rates declined dramatically after excluding extremely preterm births (<28 weeks), while elsewhere rates stayed stable. The exclusion of the extremely preterm births hardly influenced the variability in neonatal mortality rates, although a large decline was observed for the Netherlands, where active intervention is very conservative before 26 weeks of pregnancy. We did not find that countries with low mortality rates had higher proportions of extremely preterm births (which could be considered less 
preventable) and lower proportions of deaths among term or near term births.

Conclusions: Registration differences are still important contributors to variability, but these differences do not explain the variability between countries which persists after removing extremely preterm births. There were different levels and patterns of fetal and neonatal mortality between European countries.

\section{0}

\section{INCIDENCE OF AND RISK FACTORS FOR NEONATAL MORBIDITY AFTER ACTIVE PERINATAL CARE: EXTREMELY PRETERM INFANTS STUDY IN SWEDEN (EXPRESS)}

M. Norman ${ }^{1}$, M. Blennow ${ }^{1}$, F. Vineta ${ }^{2}$, A. Hellström ${ }^{3}$, L. Hellström-Westas ${ }^{4}$, G. Holmström ${ }^{4}$, K. Källén ${ }^{2}$, F. Serenius ${ }^{5}$, K. Maršál ${ }^{2}$

${ }^{1}$ Karolinska Institute, Stockholm, '2 unds University, Lund, '3niversity of Gothenburg, Gothenburg, ${ }^{4}$ Uppsala University, Uppsala, ${ }^{5}$ Umeå University, Umeå, Sweden

Aims: To determine the incidence of neonatal morbidity in extremely preterm infants and to identify associated risk factors.

Methods: Population based study of infants born before 27 gestational weeks and admitted for neonatal intensive care in Sweden during 20042007.

Results: Of 638 admitted infants, 141 died. Among these, life support was withdrawn in 55 infants because of anticipation of poor long-term outcome. Of 497 surviving infants, 10\% developed severe intraventricular haemorrhage (IVH), 5.7\% cystic periventricular leucomalacia (cPVL), 41\% septicaemia and $5.8 \%$ necrotising enterocolitis (NEC); 61\% had patent ductus arteriosus (PDA) and $34 \%$ developed retinopathy of prematurity (ROP) stage $\geq 3$. Eighty-five per cent needed mechanical ventilation and $25 \%$ developed severe bronchopulmonary dysplasia (BPD). Forty-seven per cent survived to one year of age without any severe IVH, cPVL, severe ROP, severe BPD or NEC. Tocolysis increased and prolonged mechanical ventilation decreased the chances of survival without these morbidities. Maternal smoking and higher gestational duration were associated with lower risk of severe ROP, whereas PDA and poor growth increased this risk.
Conclusions: Half of the infants surviving extremely preterm birth suffered from severe neonatal morbidities. Studies on how to reduce these morbidities and on the long-term health of survivors are warranted.

\section{1}

\section{NEONATAL COMPLICATIONS AND AUTISM SPECTRUM DISORDERS}

H.O. Atladottir ${ }^{1}$, T.B. Henriksen ${ }^{2}$, M.B. Lauritsen ${ }^{3}$, D.E. Schendel ${ }^{4}$, E.T. Parner ${ }^{5}$

${ }^{1}$ Department of Epidemiology, Institute of Public Health, University of Aarhus, Denmark, ${ }^{2}$ Perinatal Epidemiological Research Unit Department of Obstetrics and Pediatrics, Aarhus University Hospital, Skejby, Denmark, ${ }^{3}$ Regional Centre for Child and Adolescent Psychiatry, Aarhus University

Hospital, Risskov, Aarhus, Denmark, ${ }^{4}$ National

Center on Birth Defects and Developmental

Disabilities, Centers for Disease Control and

Prevention, Atlanta, GA, USA, ${ }^{5}$ Department of

Biostatistics, Institute of Public Health, Aarhus, Denmark

Background and aims: Autism spectrum disorders (ASDs) are disorders of neural development characterized by impaired social interaction and communication, and by restricted and repetitive behavior. Previous studies investigating neonatal factors and ASDs have produced inconsistent results. We performed confirmatory analyses concerning various neonatal complications and a later diagnosis with ASDs, and infantile autism, specifically.

Methods: A Danish population based cohort study, including all children born in Denmark from 1994, through 2002, a total of 604,140 children. Diagnoses of neonatal complications were retrieved from the Danish National Hospital Register. Children diagnosed with ASDs were identified using the Danish Psychiatric Central Register. Data was analyzed using Cox proportional hazards regression.

Results: A total of 4,145 children were diagnosed with ASDs, of which 1,493 had infantile autism. We found an increased risk of ASDs after exposure to a variety of neonatal complications; respiratory distress: adjusted hazard ratio $(\mathrm{HR})=1.24[95 \%$ confidence interval (Cl): 1.02-1.51], intracranial bleeding, cerebral edema or seizures: $\mathrm{HR}=1.94[95 \%$ $\mathrm{Cl}$ : 1.12-3.36], neonatal hypoglycemia: $\mathrm{HR}=1.46$ 